\title{
Impact of Marriage Over an Indian Housewife's Mental Health: Case Series
}

\author{
Dr. Nisha Khanna ${ }^{1 *}$, Nikita Khatri ${ }^{2}$
}

\section{ABSTRACT}

Being married for a young woman is considered important in India. A female is born and brought up in the country with teachings of how to be a good housewife i.e. how to be respectful to the elders, husband and in-laws. The pressure of holding onto this responsibility is detrimental to her psychological well-being and further impacts her holistic growth. The case series unfold how the lives of Indian housewives change completely after marriage, even in the contemporary times, and impacts their individuality that result in the collapse of their mental health and personality.

\section{Keywords: Marriage, Indian Housewife, Mental Health, Counselling}

I ndia is a diverse country sharing its roots in various religions and cultures. The concept of a housewife is generally a traditional conservative role of female wherein marriage is arranged or loved. As in Indian marriage, it is not about two individuals sharing a home but about coming together of two families. The Cambridge dictionary (1995) defines housewife "as a woman whose work is inside the home, doing the cleaning, cooking, etc., and who usually does not have any other job" (Cambridge Dictionary, 1995). In Indian marriages, female role is assumed to be submissive and hence she is more prone to abuse because of expectations of husband and in-laws during marriage. The abuse varies form verbal, physical, emotional and sexual. Researchers have noted that daughters are most subjected to domestic violence, both at the hands of husbands and mothers-in-law (Fernandez, 1997).

In India, couples usually live with the in-laws called as joint-families. Joint households are composed of male descendants of common ancestors who co-reside along with their spouses and children, sharing property, food and finances amongst themselves (Bharat \& D'Cruz, 2001; Chandrasekhar, 1954; Khatri, 1972, 1975; Mullatti, 1995). It is presumed in Indian families that the husband will be the bread earner of the family and will take care of the wife and the kids, whereas the wife will stay at home, and preach her husband's greatness and look after the children, family and households. Most responsibility of household work is on women and their social mobility has been restricted because of requiring approval from

\footnotetext{
${ }^{1}$ Bye Tense, India

${ }^{2}$ The University of British Columbia

*Corresponding Author
}

Received: March 12, 2021; Revision Received: April 08, 2021; Accepted: May 03, 2021

(C) 2021, Khanna N.\& Khatri N.; licensee IJIP. This is an Open Access Research distributed under the terms of the Creative Commons Attribution License (www.creativecommons.org/licenses/by/2.0), which permits unrestricted use, distribution, and reproduction in any Medium, provided the original work is properly cited. 
husbands or in-laws before taking external employment or even visiting any given place (Bharat, 2001).

The joint household system propagates the practice of arranged marriages because it gives more authority and power to the family than to the individual, and the most authority to male members of the family (Uberoi, 2004). The joint household also directs marital expectations, ensuring that relationships are focused first on the family and then on the individual (Uberoi, 2004). This prioritization of family and familial needs can also be viewed when the in-laws interfere in their routine life and also intervene in their intimate problems. Parents-in-law continue to have a strong impact on the married couple's life and privacy (Uberoi, 2004). In a hierarchical joint family arrangement, the couples are obligated to respect and follow the advice of the groom's parents, who wield considerable authority (Uberoi, 2004). As a result, the emotional needs are ignored since housewives' all time goes in taking care of her children, or in-laws, preparing meals, and doing other household chores. Not only that, but also it becomes difficult to practice personal interests for the woman or build social ties and career as utmost priority is given to the family. It is expected that she is obliged to the viewpoints of his family.

In today's time, women experience considerably more pressure as compared to Indian men to marry early, as they are considered a social and economic liability to their family (Chager, García-Román, Llópez-Gay \& Esteve, 2010). Eventually, right after the marriage, the families of both sides start expecting the birth of the first child as soon as possible, preferably a male child to build a strong familial relationship. Later on, parent in laws start to discipline the daughter-in-law and her children (their grandchildren) and place more duty of care for the household on her (Uberoi, 2004, Char, Saavala \& Kulmala, 2010).

India continues to retain its tradition of using an arranged marriage system in the twenty-first century (Jaiswal, 2014). Due to this system, the housewife has to sacrifice all her interests, passions and needs to put forth the needs of everyone else in her family including her children, husband, and in-laws. She keeps supressing her wishes, her choices, her happiness to make everyone else happy and satisfied. She mostly abides by the family rules, and keeps everyone together, by keeping aside her individual identity. Consequently, this system highly impacts her mental health and leads to psychiatric illnesses ranging from depression, anxiety, bipolar mood disorder, borderline personality disorder and substance abuse disorder, in some cases.

Asian News International (2017) defines post-marital depression as "depression that creeps in immediately or few years after marriage, is a significant problem in Indian brides. Every marriage is preceded and followed by a lot of expectations from the girl, her family and his family, and the society at large, which do not often get fulfilled (Asian News International, 2017). While the bride is always at the centre of attention during the wedding period, just after it is over, she may feel totally secluded (Asian News International, 2017). Disappointments in altered living conditions and moving away from near and dear ones can cause lot of anxiety, which is again a contributor to gradual depressive behaviour (Asian News International, 2017). Other factors like dowry expectations from the groom's family or domestic violence can make things worse, making this type of depression persistent in nature (Asian News International, 2017).

Detrimental psychological well-being not only affects the woman, but also her family, especially her children. Domestic violence refers to violence or other abuse by one person 
against another in a domestic setting, such as in marriage or cohabitation (Singh, 2018). In India, one out of every fourth Indian women is a victim of domestic violence at some point of her life or the other (Singh, 2018). It not only violates the human right but also violates one in terms of economic, health, mental and social perspective (Singh, 2018). Because of the orthodox and reckless mindset of our Indian society that "women are physically and emotionally weaker than the males", domestic violence against women in India is omnipresent and has been abounding with each passing day (Singh, 2018). All across our country, women are being tortured, beaten and killed behind the closed doors of homes (Singh, 2018).

\section{The following case series explore the impact of mental health on Indian housewives during counselling sessions. Case Study 1}

The client is a- 38- years old introverted, intelligent, caring and a loving woman who respects and obeys her parents. Her hobbies include painting and shopping. She completed her graduation in Bachelors of Commerce just to be merely occupied as her parents were not concerned about her education much because she had to get married anyway and it was only a mere form of qualification to get a well-off husband. As soon as she finished her undergraduation, her parents arranged her marriage, at an age of 23 years. She had not met the husband before marriage as she came from a conservative background and was not mentally prepared for the marriage too. After her marriage, she was unable to build an emotional connection with her husband due to her immediate pregnancy. In the first year of her marriage she gave birth to a baby. After the birth of the child, the client suffered adjustment issues ranging from the in-law's expectations, hormonal changes, the responsibility of being a mother, and building a strong relationship with her husband. After the child's birth, the husband used to sleep in the other room as the baby would wake up all night and require attention and husband had to go to work in the morning and could not sacrifice his sleep. Because of this, she used to wake up alone all night to take care of the baby and her personal needs were being sacrificed. She got little to no sleep, felt hopeless about her marriage, lost interest in painting and shopping too. Consequently, she lost her own identity as her entire life was about performing her role of being a wife, mother and an obedient daughter in-law.

Time passed on and she felt overwhelmed on and off even if they had a minor fight or argument or even if her kid asked her for a glass of water. She had suicide ideations and felt that there was no point in living. She felt dejected and could not even fight against her inlaws demands due to lack of confidence. She suppressed her needs, wishes and desires. She lost interest in physical intimacy too. Ultimately, she isolated herself with everyone as she felt that her husband was not spending any time with her, child was ignoring her and the inlaws thought that she is worthless. Because of this, her husband thought she should consult a mental health professional. She was brought into therapy by her husband for frequent crying spells and shifts in moods due to emotional instability. During the session, she explained that she has been experiencing crying spells every two days and would often go to her parent's house to change her mood. But her parents told her this is how marriage is and that she had to adjust and get used to it. Afterwards, her crying spells became frequent and hard to control. She had no friend circle due to her introvert nature as it was hard for her to put herself in social situations. Especially after marriage, she did not get the time to reconnect with old friends or make new ones. At this point, she lost all her social support.

During counselling, we put her focus back on herself and taught her how to manage time with prioritizing herself and her family time. 


\section{Case Study 2}

The client is a 35-year-old woman who married her lover, a 40-year old man, fifteen years ago. Before marriage, they had dated for five years and developed an immediate connection. They both were from different cultural backgrounds but their families were happy about them and accepted them with their blessings. The first few years of their marriage were quite happy. But, due to their mundane and monotonous life, they lost their spark. Not only that, but due to the born and brought up, she had difficulty in adjusting.

During the counselling sessions, the client revealed that her family belonged to an upper middle-class and her parents gave her everything she wanted. She was pampered and loved. Her family was very close and everyone was open about their feelings, and both the parents were doing the household chores. But her husband typically belonged to a patriarchal family system wherein the elders were conservative and over-protective for their daughters, and had strict rules for them. For example, it was expected of daughter in-laws to not wear western clothes while going the home. Moreover, they had a joint family and it was very difficult for her to manage with in-laws. In her counselling sessions, the client also shared the in-laws' over expectations, one of them was cooking for the entire family alone. She also complained about her husband's maltreatment in the form of negligence and ignorance towards her. Their 13-year-old daughter was sleeping between them which made them lose their physical intimacy. Not only that, but their child rearing practices were different. Due to the overinvolvement in the upbringing of her daughter, and household chores she is left with no time for self-management. Consequently, she had frequent quarrels with her mother in-law over these issues.

Even her husband used to criticize her for being disrespectful to his family, not doing the household chores well and trying to keep their daughter away from her grandparents. During couple consultation, the husband revealed that she is responsible for their loss of physical intimacy as every time he initiates love making, she felt that he just wants a physical relationship. This blaming of her husband reflected poorly on her self-esteem. Eventually, she started losing sleep and appetite. There were days when she would get only two hours of sleep with one proper meal a day.

During counselling, we helped her to work on her self-esteem and time-management. Her husband and in-laws started appreciating her for all the efforts she was making, which helped her to rebuild her confidence. Slowly, she got back to her happy life routine with the support of her husband and family.

\section{Case Study 3}

This case study is about a 36-year-old woman who has been married to a 39-year old man for 10 years. The husband is a lawyer and has his own law firm whereas the client is a housewife because she had to take care of their two sons. Like every other family they did have their share of highs and lows but nothing too serious until about a year ago.

The client visited the mental health professional because of an issue of dominating motherin-law and because she felt overly subdued because of her. In the visit with the mental health professional, she explained that she gives "so much time to" her partner but "he just does not bother." She felt a lacuna in her relationship with her partner but initially did not pay attention to it, until she realized that they had stopped interacting at all; once it continued for a week. They were often getting into frequent conflicts. She was unable to balance her married life and mental health.

(c) The International Journal of Indian Psychology, ISSN 2348-5396 (e)| ISSN: 2349-3429 (p) | 261 
The mental health professional told her that she invested too much in her family and household whereas her husband had no involvement in the household chores which was the main reason of their clash. She felt negligence as he spent more time with the kids or his parents and not with her. Unknowingly she had become so possessive about her partner because he spent the least time with her. Her over-obsession pushed her away from her husband and children unconsciously. She started nagging, cribbing and controlling them which further leads to frequent arguments with everyone in the house.

During counselling, we made her realize the importance of love thyself and helped her to manage her energy and time on self more and in the result, she started doing things that made her truly happy.

\section{CONCLUSION}

Through the case studies, we can conclude that marriage has significant effects on woman's mental health. It is common that Indian housewives' lives are more about husband, children, in-laws and relatives rather than themselves or their needs. This leads to poor psychological well-being of women, poor management of their self and time, frustration, and psychiatric conditions most commonly stress, depression, anxiety, and mood swings.

This case series is significant because it impacts many Indian women's holistic growth and their perception of social reality. By understanding these issues and through counselling/therapy, Indian women can be taught how to live a happy and balanced life and how to prioritize self along with family needs. Women need to be self-aware and properly guided through counselling which can help them to balance happiness of self and others so that they won't lose their individuality or identity. Future studies can explain this relationship between housewife's mental health and counselling.

\section{Limitation}

This case analysis focuses on heterosexual couples and does not give an account of homosexual marriages. This case analysis is also gender specific i.e. it gives viewpoints of one gender (female) only. The case examples used in this study were of women who came for therapy and although the concepts discussed are common for many women, it only takes into account the details of the women who chose to participate. Future studies should conduct structured interviews of housewives inclusive of those who go for therapy or don't go for therapy but have the similar concerns.

\section{REFERENCES}

Asian News International. Some kind of depression indian women face. (2017). Asian News International

Bharat, S. \& D'Cruz, P. (2001). Beyond joint and nuclear: The Indian family revisited. Journal of Comparative Family Studies, 32, 167-194.

CambridgeDictionary. (1995). Housewife. Cambridge Dictionary.

Chager, S., García-Román, J., Llópez-Gay, A. \& Esteve, A. (2010). Educational expansion and early marriage in India: Time and regional trends. Papers de Demografia, 373, 1-39.

Char, A., Saavala, M. \& Kulmala, T. (2010). Influence of mothers-in-law on young couples' family planning decision in rural India. Reproductive Health Matters, $18,154-62$. 
Fernandez-Ballesteros, R., Zamarron, M. \& Ruiz, M. (2001). The contribution of sociodemographic and psychosocial factors to life satisfaction. Ageing and Society, 21, 25-43.

Fernandez, M. (1997). Domestic violence by extended family members in India: Interplay of gender and generation. Journal of Interpersonal Violence, 12, 433-455.

Jaiswal, T. (2014). Indian arranged marriages: A social psychological perspective Routledge.

Singh, R., Ritu Singh, Kusha Pant, \& Amit K Mishra. (03/01/2018). Domestic violence act "shield or weapon of an indian women": Two sides of a coin Indian Association of Health, Research and Welfare. doi:10.15614/ijpp. v9i01.11765

Uberoi, P. (2004). The family in India. In Das, V. Handbook of Indian Sociology. New Delhi: Oxford.

\section{Acknowledgement}

The author(s) appreciates all those who participated in the study and helped to facilitate the research process.

\section{Conflict of Interest}

The author(s) declared no conflict of interest.

How to cite this article: Khanna N. \& Khatri N. (2021). Impact of Marriage Over an Indian Housewife's Mental Health: Case Series. International Journal of Indian Psychology, 9(2), 258-263. DIP:18.01.031.20210902, DOI:10.25215/0902.031 